\title{
WAT-free mice: diabetes without obesity
}

\author{
Steven L. McKnight ${ }^{1}$ \\ Department of Biochemistry, University of Texas Southwestern Medical Center, Dallas, Texas 75235-9152 USA
}

Two papers appearing in this issue report the generation of transgenic mice largely devoid of white adipose tissue (WAT). In both cases the resulting mice display anatomical and physiological properties very similar to human patients suffering from generalized lipodystrophy. Such patients lack WAT, a condition resulting from either genetic or autoimmune etiologies, and are severely diabetic (Foster 1994; Seip and Trygstad 1996). The present reports provide fresh and interesting observations regarding the physiological consequences of life without fat and, moreover, establish animal models that offer new opportunities for the study of type 2 diabetes.

How was it possible to engineer WAT-free laboratory mice? The two teams, headed by Brown and Goldstein in Texas (Shimomura et al. 1998) and Vinson at the National Institutes of Health (NIH) (Moitra et al. 1998), attacked the problem using similar strategies. The Texans directed adipocyte-specific expression of a truncated, constitutively active form of SREBP1c, a transcription factor involved in the regulation of genes required for the biosynthesis of both cholesterol and fatty acids. The Federalists likewise directed the expression of a modified transcription factor in WAT. In the latter case, the team utilized clever methods to inhibit the function of endogenous members of the Jun and CCAAT/enhancer-binding protein $(\mathrm{C} / \mathrm{EBP})$ families of transcription factors. Expression of these dominant-positive and dominant-negative transcription factors were similarly directed to brown adipose tissue (BAT) and WAT by the use of regulatory sequences associated with the adipocyte-specific aP2 gene (Ross et al. 1990). The resulting transgenic mice were remarkably similar-WAT-free, profoundly insulin resistant, and rampantly diabetic.

Before delving into the interesting physiological and anatomical abnormalities observed in WAT-free mice, it is useful to review the respective experimental approaches in the context of the gene regulatory pathways that were perturbed. Moitra and colleagues made use of an artificial transcription factor designated A-ZIP/F. In vitro assays had already demonstrated that the A-ZIP/F protein functions as an inhibitor of various members of the bZip family of transcription factors (Krylov et al. 1997). The A-ZIP/F protein started with the leucine zipper of $\mathrm{C} / \mathrm{EBP} \alpha$, which was modified so as to dimerize promiscuously with all members of the C/EBP and Jun

1E-MAIL smckni@biochem.swmed.edu; FAX (214) 648-3346. families of transcription factors. The protein was further manipulated to replace the $\mathrm{C} / \mathrm{EBP} \alpha$ basic region, normally employed to establish direct DNA contact, with an acidic, amphipathic $\alpha$-helix. The resulting protein maintains the ability to dimerize with the leucine zippers of all C/EBP and Jun family members. A-ZIP/F further establishes an unusually stable interaction with unadulterated bZip partners as a result of formation of a continuous, coiled-coil dimer interface, including the leucine zipper and a paired basic/acidic alpha helical extension.

Extensive evidence has demonstrated the activities of C/EBP family members in the growth and differentiation of WAT. For example, forced expression of either C/ EBP $\alpha$ (Samuelsson et al. 1991; Umek et al. 1991; Freytag and Geddes 1992; Freytag et al. 1994) or C/EBPß (Yeh et al. 1995) has been reported to enhance adipogenesis of cultured fibroblasts. Likewise, antisense C/EBP $\alpha$ RNA has been shown to suppress coordinate, adipocyte-specific gene expression and triglyceride accumulation during differentiation of 3T3-L1 preadipocytes (Lin and Lane 1992). Finally, gene knockout studies have reported that $\mathrm{C} / \mathrm{EBP} \alpha$-deficient mice are devoid of WAT (Wang et al. 1995), and that mice doubly deficient in both C/EBP $\beta$ and C/EBP $\delta$ display reduced fat mass (Tanaka et al. 1997). The present observations of Vinson and colleagues are therefore straightforward and sensible. By directing the expression of the inhibitory A-ZIP/F protein to WAT, a gene regulatory cascade essential for terminal adipocyte differentiation is impeded, resulting in fat-free mice. This approach offers a valuable step forward from the earlier C/EBP $\alpha$ knockout experiments of Darlington and colleagues (Wang et al. 1995). Because C/EBP $\alpha$ is also expressed in the liver, gut, and other tissues essential for energy homeostasis, animals fully deficient in this transcription factor die from hypoglycemia shortly after birth. As such, WAT-free, C/EBP $\alpha$-deficient animals can not be studied using traditional physiological approaches.

The WAT-free phenotype observed by Shimomura and colleagues following forced, adipocyte-specific expression of a constitutively active form of SREBP1c was less clearly anticipated. Indeed, as will be discussed subsequently, it might have been expected that this manipulation would enhance adipogenesis. This dilemma calls for a brief review of previous studies on the SREBP family of transcription factors (for more detail, see Brown and Goldstein 1997). The origin of the SREBPs stems 
from studies of the gene encoding the low density lipoprotein (LDL) receptor. Transcription of the LDL receptor gene is elevated in cells starved for cholesterol. This observation led to the discovery of a cis-regulatory DNA sequence, designated the sterol response element (SRE), that is necessary for transcriptional induction of the receptor gene upon cholesterol starvation. A DNA-binding activity designated SRE-binding protein (SREBP) was purified and partially sequenced, leading to the cloning of its encoding gene. Not unlike many other mammalian transcription factors, the SREBPs come in a variety of isoforms encoded by two distinct genes, designated SREBP1 and SREBP2. The SREBP1 gene directs, by alternative splicing, isoforms designated SREBP1a and SREBP1c, with the former having a more potent activation domain than the latter.

Biochemical and molecular biological studies of SREBP have unveiled a novel pathway by which its activity is regulated in response to the availability of cholesterol. The mature forms of SREBP, which appear under conditions of cholesterol starvation, are conventional transcription factors containing a bHLH-Zip DNA binding domain and an acidic activation domain. When cholesterol levels are abundant, however, all SREBP isoforms exist as immature precursors. Latent SREBPs are much larger polypeptides that attach to the endoplasmic reticulum via two membrane spanning segments. Upon cholesterol starvation the immature precursors are cleaved by a sterol-sensitive proteolytic event, resulting in the release of a mature, amino-terminal fragment that enters the nucleus and orchestrates the coordinate activation of genes required for the biosynthesis of cholesterol and fatty acids.

SREBP1c was independently discovered by Spiegelman and colleagues in an expression screen for proteins that bind to an E-box sequence in the promoter of the gene encoding fatty acid synthase (Tontonoz et al. 1993). Forced expression of SREBP1c in 3T3-L1 cells has been reported to enhance fatty acid biosynthesis and adipocyte differentiation (Kim and Spiegelman 1996), leading to the designation of this transcription factor as adipocyte determination and differentiation factor-1 (ADD-1).

Because SREBP1c/ADD-1 is expressed in the WAT of laboratory mice, it is most sensible to hypothesize that this transcription factor should play a stimulatory role in adipogenesis. It thus comes as some surprise to find that transgenic animals expressing a dominant-positive (mature) form of SREBP1c are compromised with respect to WAT abundance and maturity. When assayed shortly after birth, the adipose tissue of transgenic, experimental animals appeared similar to control littermates-scanty and immature. By 6 weeks of age, however, the WAT of control animals developed its normal mature appearance, whereas that of the SREBP1c-expressing, transgenic animals continued to resemble the immature WAT seen shortly after birth (see Shimomura et al. 1998). Compared with the A-ZIP/F-expressing mice, which are born with no metabolic WAT and fail to develop any throughout life, the impediment to WAT development appears less severe in the case of the Texas mice. It will become clear, however, that both lines of transgenic mice suffer very similar physiological perturbations that closely mimic lipodystrophy in humans.

Why does forced expression of a dominant-positive form of SREBP1c impede formation of mature WAT? Clues to this enigma come from the extensive series of Northern blot assays conducted by Shimomura and colleagues (1998). Compared with normal mice, transgenic animals forced to express the mature form of SREBP1c contain substantially reduced levels of a number of gene products essential for maturation and function of WAT. Significant reductions were observed for the mRNAs encoding PPAR $\gamma, \mathrm{C} / \mathrm{EBP} \alpha$, leptin, insulin receptor, insulin receptor substrate 1 , insulin receptor substrate 2 , and the GLUT4 glucose transporter. Given this wide range of effects it is not surprising that the experimental animals would suffer impediments in the formation of WAT.

In contrast to the many WAT-specific mRNAs that were observed to be substantially reduced in transgenic animals expressing the mature form of SREBP1c, two specific mRNA were expressed at an increased level in the residual WAT of experimental animals relative to control animals. These include the mRNAs for tumor necrosis factor- $\alpha(\mathrm{TNF} \alpha)$ and preadipocyte factor 1 (Pref1). It is unclear how either of these gene products might functionally impede adipocyte maturation. It is interesting, however, that elevated levels of TNF $\alpha$ have been implicated in the genesis of insulin resistance (Hotamisligil and Spiegelman 1994). Likewise, elevated Pref-1 levels point to the possibility that forced expression of mature SREBP1c may block adipocytes at an immature stage of differentiation. Intriguingly, forced expression of Pref-1, a cell surface protein that contains epidermal growth factor-like repeats and is expressed exclusively in immature adipocytes, has been reported to impede adipocyte maturation in cell culture assays (Smas and Sul 1993).

What consequences result when a laboratory mouse is WAT-free? Not surprisingly, the answers to this question were fully anticipated by clinical scientists who have studied lipodystrophic patients for the past century (for review, see Seip and Trygstad 1996). Humans suffering from congenital or acquired lipodystrophy become severely diabetic, have voracious appetites, are hypermetabolic, and display an anabolic syndrome that includes organomegaly of the liver, spleen, pancreas, and kidney. These conditions perfectly describe the WATfree mice developed respectively in Texas and the NIH. Both papers provide compelling evidence that WAT-free mice are rampantly diabetic as judged by a thorough series of physiological assays. Moreover, both models show organomegaly-including fatty livers. Indeed, the anatomical and physiological properties of the two lines of mice differ in but one notable aspect. Even by birth the Texas mice contain a massive enlargement of BAT, with continued hyperplastic growth of this tissue during postnatal and adult development. This was not the case with the NIH mice. Although residual adipose tissue present in the latter animals resembled BAT, it was not hyperplastic. Finally, the BAT of both animals appeared to be 
metabolically inactive with respect to thermogenesis. BAT coloration was faded in a manner consistent with a reduced density of mitochondria. Moreover, Northern blot assays conducted in both studies revealed very marked reductions in the expression of the UCP1 mRNA.

Now basic scientists can begin to think about a syndrome that clinical scientists have recognized and studied for decades. Moreover, the field is now provided with animal models that can be used to extend studies of lipodystrophic diabetes. For the novices, including me, it comes as some surprise that WAT-free mammals are diabetic. Having been schooled to believe that diabetes is a disease of the obese, the uninitiated might anticipate that the WAT-free condition would correspond to an antidiabetic state. One simplistic take-home lesson is that type 2 diabetes can result from an imbalance in the abundance of WAT-too little, just as too much, is unhealthy.

This begs, however, the question of what is the culprit? Several candidates bear consideration, including TNF $\alpha$ and free fatty acids (FFAs). Spiegelman and colleagues have contributed extensive evidence that TNF $\alpha$ can impede signaling by the insulin receptor (Hotamisligil and Spiegelman 1994). Whether the modest increase in TNF $\alpha$ expression observed at the mRNA level in WAT-free mice is sufficient to account for their diabetic state remains open to question. McGarry and colleagues have developed the concept that type 2 diabetes may result from an increase in circulating levels of FFAs (for review, see McGarry 1994). The mice studied by Moitre et al. show modest elevations in FFAs in the fed state, but those studied by Shimomura and colleagues do not. Similarly, some human patients suffering from lipodystrophy have elevated FFAs, whereas other equally insulin resistant patients have normal FFA levels (Seip and Trygstad 1996).

Having closed with a listing of two candidate molecules to consider as diabetes 'promoting factors,' it is encouraging to recognize that the field now has several well-developed animal models that may open new doors to the study of type 2 diabetes. Indeed, the recent work of Graves and colleagues (Burant et al. 1997) has begun to show the utility of this pathway. Transgenic mice expressing the A chain of diptheria toxin in BAT and WAT lose adipose tissue as they age, resulting in similar, if less dramatic, anatomical and physiological perturbations as reported by Moitra et al. (1998) and Shimomura et al. (1998). Graves and colleagues used these adipose attenuated mice to ask whether insulin sensitivity could be restored in response to troglitazone. Torglitazone is a member of the thiazolidinedione (TZD) class of compounds that represent a new and exciting class of antidiabetic drugs. TZDs are specific and potent ligands for PPAR $y$ and have been found to promote both weight gain in rodents and adipocyte differentiation in cultured cell models. It was therefore reasonable to anticipate that TZDs might not be effective in treating the diabetic symptoms of WAT-depleted mice. Remarkably, Graves and colleagues have demonstrated that troglitazone restores insulin sensitivity, alleviates hyperglycemia, and lowers serum cholesterol, triglycerides, and FFAs in WAT-depleted mice. If correct, these observations indicate that adipose tissue is not the target of TZDs.

At the very least, the present work on WAT-free mice should favor a closer and more productive relationship between basic reserach and clinical scientists. One can rest assured, for example, that basic scientists interested in the molecular underpinnings of type 2 diabetes will keep a close watch on the gene hunt for mutations that cause congenital lipodystrophy.

\section{References}

Burant, C.F., S. Sreenan, K. Hirano, T.C. Tai, J. Lohmiller, J. Lukens, N.O. Davidson, S. Ross, and R.A. Graves. 1997. Troglitazone action is independent of adipose tissue. J. Clin. Invest. 100: 2900-2908.

Foster, D.W. 1994. The lipodystrophies and other rare disorders of adipose tissue. In Harrison's principles of internal medicine (ed. K.J. Isselbacher, E. Braunwald, J.D. Wilson, J.B. Martin, A.S. Fauci, and D.L. Kasper), pp. 2131-2136. McGrawHill, New York, NY.

Freytag, S. and T. Geddes. 1992. Reciprocal regulation of adipogenesis by Myc and C/EBP $\alpha$. Science 256: 379-382.

Freytag, S.O., D.L. Paielli, and J.D. Gilbert. 1994. Ectopic expression of the CCAAT/enhancer-binding protein alpha promotes the adipogenic program in a variety of mouse fibroblastic cells. Genes \& Dev. 8: 1654-1663.

Hotamisligil, G.S. and B.M. Spiegelman. 1994. Tumor necrosis factor alpha: A key component of the obesity-diabetes link. Diabetes 43: 1271-1278.

Kim, J.B. and B.M. Spiegelman. 1996. ADD1/SREBP1 promotes adipocyte differentiation and gene expression linked to fatty acid metabolism. Genes \& Dev. 10: 1096-1107.

Krylov, D., K. Kasai, D.R. Echlin, E.J. Taparowsky, H. Arnheiter, and C. Vinson. 1997. A general method to design dominant negatives to B-HLHZip proteins that abolish DNA binding. Proc. Natl. Acad. Sci. 94: 12274-12279.

Lin, F.T. and M.D. Lane. 1992. Antisense CCAAT/enhancerbinding protein RNA suppresses coordinate gene expression and triglyceride accumulation during differentiation of 3T3L1 preadipocytes. Genes \& Dev. 6: 533-544.

McGarry, J.D. 1994. Disordered metabolism in diabetes: Have we under-emphasized the fat component? I. Cell. Biochem. 55: 29-38.

Moitra, J., M.M. Mason, M. Olive, D. Krylov, O. Gavrilova, B. Marcus-Samuels, L. Feigenbaum, H. Westphal, T. Aoyama, M. Eckhaus, M.L. Reitman, and C. Vinson. 1998. Life without fat: A transgenic mouse. Genes \& Dev. (this issue).

Ross, S.R., R.A. Graves, A. Greenstein, K.A. Platt, H.L. Shyu, B. Mellovitz, and B.M. Spiegelman. 1990. A fat-specific enhancer is the primary determinant of gene expression for adipocyte P2 in vivo. Proc. Natl. Acad. Sci. 87: 9590-9594.

Samuelsson, L., K. Stromberg, K. Vikman, G. Bjursell, and S. Enerback. 1991. The CCAAT/enhancer binding protein and its role in adipocyte differentiation: Evidence for direct involvement in terminal adipocyte development. EMBO $\mathrm{T}$. 10: 3787-3793.

Seip, M. and O. Trygstad. 1996. Generalized lipodystrophy, congenital and acquired (lipoatrophy). Acta Paediatr. Scand. Suppl. 413: 2-28.

Shimomura, I., R.E. Hammer, J.A. Richardson, S. Ikemoto, Y. Bashmakov, J.L. Goldstein, and M.S. Brown. 1998. Insulin resistance and diabetes mellitus in transgenic mice express- 
ing nuclear SREBP-1c in adipose tissue: model for congenital generalized lipodystrophy. Genes \& Dev. (this issue).

Smas, C.M. and H.S. Sul. 1993. Pref-1, a protein containing EGFlike repeats, inhibits adipocyte differentiation. Cell 73: 725734.

Tanaka, T., N. Yoshida, T. Kishimoto, and S. Akira. 1997. Defective adipocyte differentiation in mice lacking the C/EBP $\beta$ and/or C/EBPS gene. EMBO J. 16: 7432-7443.

Tontonoz, P., J.B. Kim, R.A. Graves, and B.M. Spiegelman. 1993. ADD1: A novel helix-loop-helix transcription factor associated with adipocyte determination and differentiation. Mol. Cell. Biol. 13: 4753-4759.

Umek, R.M., A.D. Friedman, and S.L. McKnight. 1991. CCAAT-enhancer binding protein: a component of a differentiation switch. Science 251: 288-292.

Wang, N.D., M.J. Finegold, A. Bradley, C.N. Ou, S.V. Abdelsayed, M.D. Wilde, L.R. Taylor, D.R. Wilson, and G.J. Darlington. 1995. Impaired energy homeostasis in C/EBP alpha knockout mice. Science 269: 1108-1112.

Yeh, W., Z. Cao, M. Classon, and S.L. McKnight. 1995. Cascade regulation of terminal adipocyte differentiation by three members of the C/EBP family of leucine zipper proteins. Genes \& Dev. 9: 168-181. 


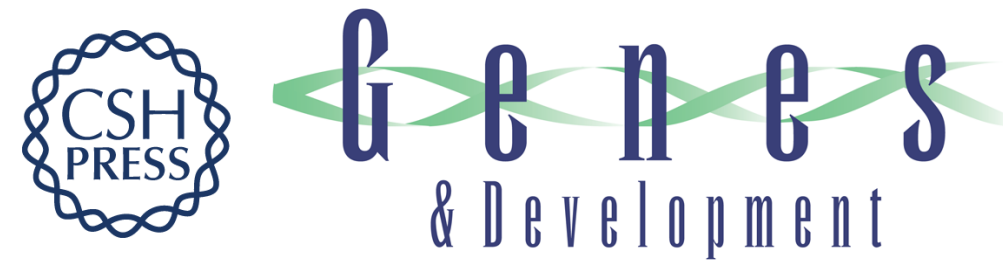

\section{WAT-free mice: diabetes without obesity}

Steven L. McKnight

Genes Dev. 1998, 12:

Access the most recent version at doi:10.1101/gad.12.20.3145

References This article cites 17 articles, 12 of which can be accessed free at: http://genesdev.cshlp.org/content/12/20/3145.full.html\#ref-list-1

License

Email Alerting Receive free email alerts when new articles cite this article - sign up in the box at the top Service right corner of the article or click here.

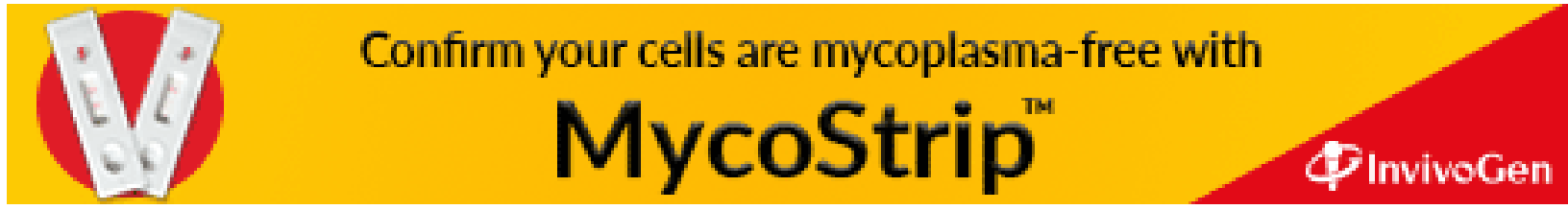

